\title{
Epirubicin enhances TRAIL-induced apoptosis in gastric cancer cells by promoting death receptor clustering in lipid rafts
}

\author{
LING XU, XIUJUAN QU, YING LUO, YE ZHANG, JING LIU, JINGLEI QU, LINGYUN ZHANG and YUNPENG LIU \\ Department of Medical Oncology, the First Hospital of China Medical University, Shenyang 110001, P.R. China
}

Received December 16, 2010; Accepted February 4, 2011

DOI: $10.3892 / \mathrm{mmr} .2011 .439$

\begin{abstract}
Gastric cancer cells are usually insensitive to tumor necrosis factor-related apoptosis-inducing ligand (TRAIL). In the present study, in MGC803 cells treated with $100 \mathrm{ng} / \mathrm{ml}$ TRAIL for $24 \mathrm{~h}$, the inhibition rate of cell proliferation was $9.76 \pm 2.39 \%$ and the rate of cell apoptosis was only $4.37 \pm 1.45 \%$. Treatment with epirubicin $\left(1.18 \mu \mathrm{g} / \mathrm{ml}, \mathrm{IC}_{50}\right.$ dose for $\left.24 \mathrm{~h}\right)$ and TRAIL (100 ng/ml for $24 \mathrm{~h}$ ) led to a marked increase in the inhibition rate of cell proliferation and apoptosis compared to treatment with epirubicin or TRAIL alone $(\mathrm{P}<0.05)$. Moreover, even more notable cleavage of caspase- 3 and 8 was detected with the combination of epirubicin and TRAIL. TRAIL $(100 \mathrm{ng} / \mathrm{ml})$ induced only light lipid raft aggregation and DR4 and DR5 clustering. Epirubicin significantly promoted lipid raft DR4 and DR5 aggregation, as well as the localization of DR4 and DR5 in the lipid rafts. Similar results were detected with the combination of epirubicin and TRAIL. Pretreatment with $50 \mu \mathrm{g} / \mathrm{ml}$ nystatin, a cholesterol-sequestering agent, partially prevented epirubicin-induced lipid raft aggregation and DR4 and DR5 clustering. Pretreatment with nystatin did not markedly inhibit epirubicin-induced apoptosis, while nystatin partially suppressed epirubicin and TRAIL-induced apoptosis $(\mathrm{P}<0.05)$. Our data demonstrate that epirubicin enhanced TRAIL-induced apoptosis in gastric cancer MGC803 cells, at least partially, through death receptor redistribution in the lipid rafts.
\end{abstract}

\section{Introduction}

The incidence of gastric cancer is very high in East Asia, particularly in China (1). Although chemotherapy improves the survival of patients with advanced gastric cancer, the overall survival is no more than one year (2); therefore, the development of novel therapeutic methods is a priority. Tumor necrosis factor-related apoptosis-inducing ligand (TRAIL) is a member of the tumor necrosis factor (TNF) family. TRAIL is known to

Correspondence to: Dr Yunpeng Liu, Department of Medical Oncology, the First Hospital of China Medical University, Shenyang 110001, P.R. China

E-mail: cmuliuyunpeng@yahoo.cn

Key words: tumor necrosis factor-related apoptosis-inducing ligand, epirubicin, gastric cancer, apoptosis, lipid rafts induce apoptosis in many cancer cells without causing significant toxicity to normal cells. TRAIL triggers apoptosis upon engagement of two receptors named death receptor 4 (DR4) and death receptor 5 (DR5). In response to TRAIL, death receptors recruit the Fas-associated death domain (FADD) and procaspase- 8 and -10 , hence forming the macromolecular complex, termed the death-inducing signaling complex (DISC). Within this complex, procaspase- 8 and -10 are activated and initiate the caspase cascade, leading to apoptosis $(3,4)$. However, previous studies including our own have reported that gastric cancer cells are insensitive to TRAIL (5-7).

Recent studies suggest that lipid rafts serve as plasma membrane platforms for death receptor-initiated signals $(8,9)$. Lipid rafts are rich in cholesterol and sphingolipids, and are thus more tightly packaged than the non-raft phase of the plasma membrane (10). Song et al have found that the disruption of lipid rafts inhibits TRAIL-induced apoptosis in lung cancer cell lines (11). A recent study by our group demonstrated that TRAIL does not induce effective lipid raft aggregation capable of triggering apoptosis in gastric cancer cells (7). This implies that lipid raft dysfunction is a potential reason for the resistance of gastric cancer cells to TRAIL.

Some chemotherapeutic drugs, such as paclitaxel, doxorubicin and cisplatin, have been reported to sensitize cancer cells to TRAIL-induced apoptosis (12-14). An epirubicin-based ECF regimen achieves a significant effect in the treatment of patients with advanced gastric cancer $(15,16)$. Our recent study showed that oxaliplatin enhances TRAIL sensitivity by clustering death receptors into lipid rafts (7). Aroui et al reported that doxorubicin sensitizes breast cancer cells to TRAIL by triggering lipid raft aggregation (17). Doxorubicin and epirubicin are both anthracyclines, but whether epirubicin is capable of regulating lipid rafts and thus enhancing the sensitivity of gastric cancer cells to TRAIL remains to be determined.

In the present study, the results indicate that epirubicin enhances TRAIL-induced apoptosis in gastric cancer MGC803 cells, at least partially, through death receptor redistribution in lipid rafts.

\section{Materials and methods}

Reagents and antibodies. Recombinant human TRAIL/Apo2L was purchased from Cytolab/Peprotech Asia (USA). The fluorescein isothiocyanate (FITC)-conjugated cholera toxin B subunit from Vibrio cholerae was from Sigma Chemical Co. Rhodamineconjugated goat anti-mouse IgG, anti-DR4, anti-DR5, anti-actin, 
A

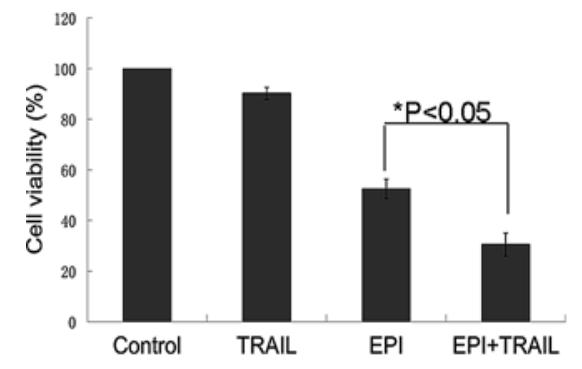

B

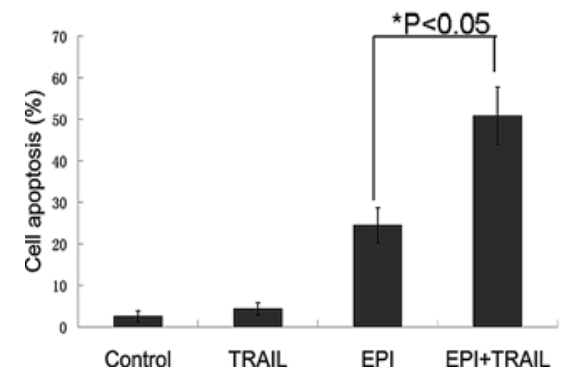

C Control TRAIL EPI EPI+TRAIL
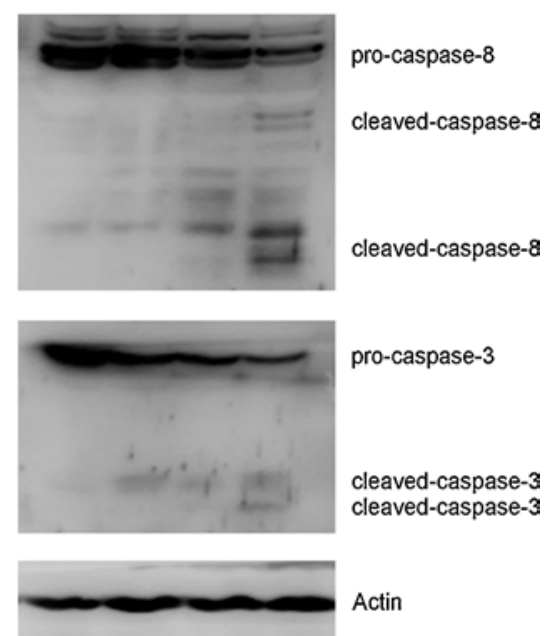

Figure 1. Epirubicin and TRAIL synergistically affected cell viability and cell apoptosis in MGC803 cells. MGC803 cells were left untreated or treated with $1.18 \mu \mathrm{g} / \mathrm{ml}$ epirubicin, $100 \mathrm{ng} / \mathrm{ml}$ TRAIL, or a combination of both for $24 \mathrm{~h}$. (A) Cell viability was determined by the MTT assay. (B) The percentage of apoptotic cells was quantitated by flow cytometry. (C) The expression of caspase- 3 and -8 proteins was analyzed by Western blotting.

anti-caspase-3 and anti-caspase-8 antibodies were from Santa Cruz Biotechnology (Santa Cruz, CA, USA).

Cell cultures. Human gastric cancer MGC803 cells were obtained from the Type Culture Collection of the Chinese Academy of Sciences (Shanghai, China). The cells were cultured in RPMI-1640 medium (Gibco) containing 10\% heatinactivated fetal bovine serum (FBS), penicillin $(100 \mathrm{U} / \mathrm{ml})$, and streptomycin $(100 \mathrm{mg} / \mathrm{ml})$ at $37^{\circ} \mathrm{C}$ under an atmosphere of $95 \%$ air and $5 \% \mathrm{CO}_{2}$.

MTT assay. Cell viability was measured using a 3-(4, 5-dimethyl thiazol-2-yl)-2,5-diphenyl tetrazolium bromide (MTT) assay. The cells were seeded at $5 \times 10^{4}$ cells/well in 96-well plates and then exposed to epirubicin and/or TRAIL. Subsequently, $25 \mu \mathrm{l}$ of MTT solution $(5 \mathrm{mg} / \mathrm{ml})$ was added to each well and the cells were incubated for another $4 \mathrm{~h}$ at $37^{\circ} \mathrm{C}$. After the removal of the culture medium, the cells were lysed in $200 \mu 1$ dimethylsulfoxide (DMSO), and the optical density (OD) was measured at $570 \mathrm{~nm}$ with a microplate reader (Model 550, Bio-Rad Laboratories, USA).

Flow cytometric analysis. The cells were seeded at $3 \times 10^{5}$ cells/well in 6-well plates and exposed to epirubicin and/or TRAIL. After being fixed with ice-cold $70 \%$ ethanol for $12 \mathrm{~h}$, the samples were washed twice with PBS and then incubated with $20 \mu \mathrm{g} / \mathrm{ml}$ RNase A and $10 \mu \mathrm{g} / \mathrm{ml}$ propidium iodide (PI) at $37^{\circ} \mathrm{C}$ for $30 \mathrm{~min}$ in the dark. Finally, the samples were evaluated by flow cytometry and the data were analyzed using WinMDI software.

Western blot analysis. The cells were solubilized in $1 \%$ Triton lysis buffer on ice. Cell lysate proteins were separated by sodium dodecyl sulfate-polyacrylamide gel electrophoresis and electrophoretically transferred to nitrocellulose membrane (Immoblin-P; Millipore, Bedford, MA, USA). The membranes were blocked with 5\% skim milk in TBST buffer, incubated with the indicated primary antibodies and reacted with horseradish-peroxidaseconjugated secondary antibodies. The immunoreactive proteins were visualized with enhanced chemiluminescence reagent (SuperSignal West Pico Chemiluminescent Substrate, Pierce, IL, USA).

Immunofluorescence microscopy. The cells were seeded and treated in Lab-Tek chamber slides (Nunc S/A, Polylabo, Strasbourg, France), fixed in $3.3 \%$ paraformaldehyde for $20 \mathrm{~min}$, and blocked with 5\% bovine serum albumin in PBS. For double staining, the cells were primed with FITC-conjugated rabbit-anti cholera toxin B subunit, anti-DR4, or anti-DR5 mouse monoclonal antibody for $1 \mathrm{~h}$, and then incubated with Rhodamine-conjugated goat anti-mouse IgG for $45 \mathrm{~min}$. The cells were mounted using the SlowFade Antifade kit (Molecular Probes, Eugene, OR, USA), and analyzed by confocal fluorescence microscopy (FV1000S-SIM/IX81, Olympus, Japan).

Statistical analysis. All experiments were repeated at least three times. Data are expressed as the means \pm SD. Differences in the results between two groups were evaluated using the Student's t-test. $\mathrm{P}<0.05$ was considered to be statistically significant.

\section{Results}

Epirubicin enhances TRAIL-induced apoptosis of MGC803 cells. MGC803 cells were treated with $100 \mathrm{ng} / \mathrm{ml}$ TRAIL for $24 \mathrm{~h}$, the inhibition rate of cell proliferation was only $9.76 \pm 2.39 \%$. Treatment with the combination of epirubicin $\left(1.18 \mu \mathrm{g} / \mathrm{ml}, \mathrm{IC}_{50}\right.$ dose of $\left.24 \mathrm{~h}\right)$ and TRAIL (100 $\left.\mathrm{ng} / \mathrm{ml}\right)$ leaded to an obvious increase in the inhibition rate of cell proliferation compared to treatment with epirubicin alone $(69.52 \pm 4.49 \%$ vs. $47.51 \pm 3.89 \%, \mathrm{P}<0.05)$ (Fig. 1A). TRAIL (100 ng/ml) and epirubicin $(1.18 \mu \mathrm{g} / \mathrm{ml})$ were used for the following experiments. The exposure of TRAIL for $24 \mathrm{~h}$ induced $4.37 \pm 1.45 \%$ of cell apoptosis. Treatment with epirubicin and TRAIL resulted in a dramatic increase in cell apoptosis compared to treatment with epirubicin alone $(50.88 \pm 6.87 \%$ vs. $24.46 \pm 4.24 \%, \mathrm{P}<0.05)$ (Fig. 1B). TRAIL alone induce little cleavage of caspase-3 and -8. Treatment with epirubicin and TRAIL resulted in more significant activation of caspase- 3 and -8 compared to 


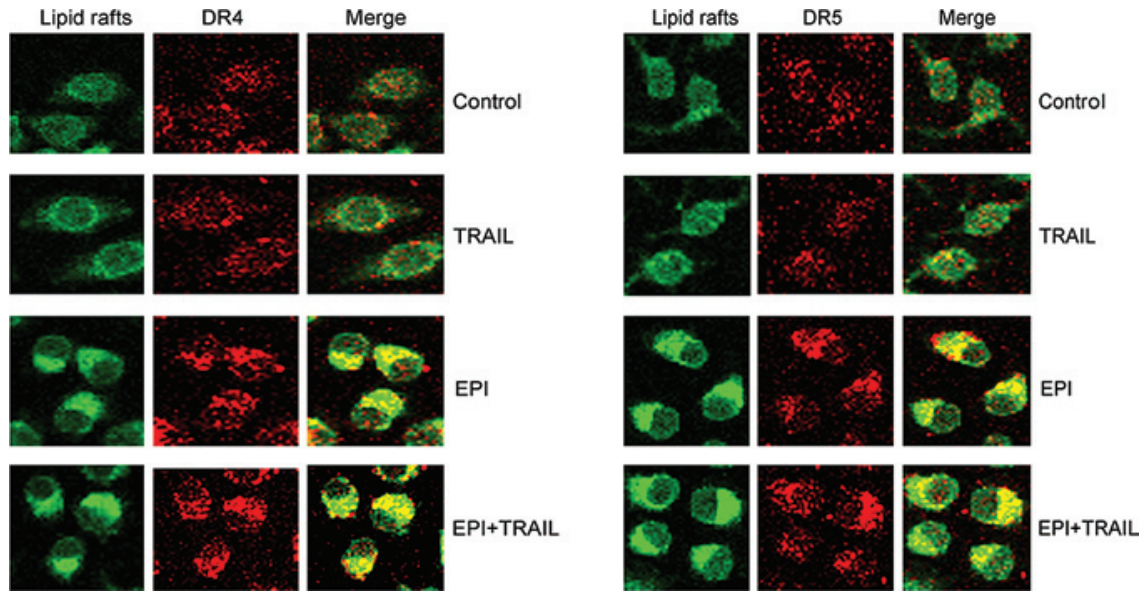

Figure 2. Epirubicin promoted DR4 and DR5 clustering into lipid rafts in MGC803 cells. Cells were left untreated or treated with $1.18 \mu \mathrm{g} / \mathrm{ml}$ epirubicin, $100 \mathrm{ng} / \mathrm{ml}$ TRAIL, or a combination of both for $16 \mathrm{~h}$. Localization of lipid rafts, DR4 or DR5 was visualized using confocal fluorescence microscopy. Representative images. Original magnification, $\mathrm{x} 40$.

A
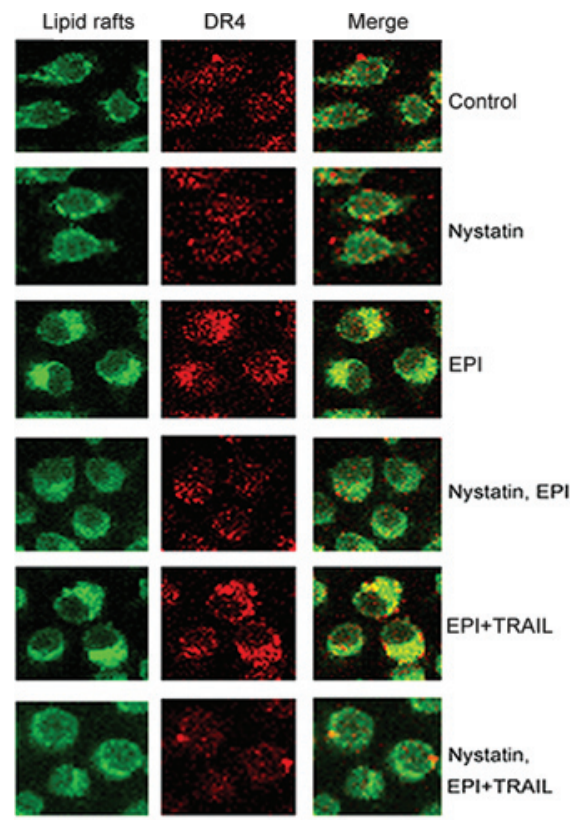
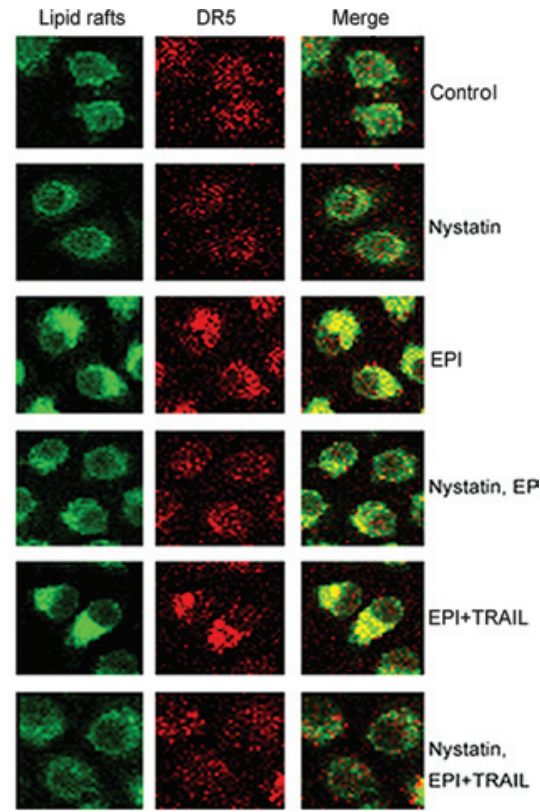

B

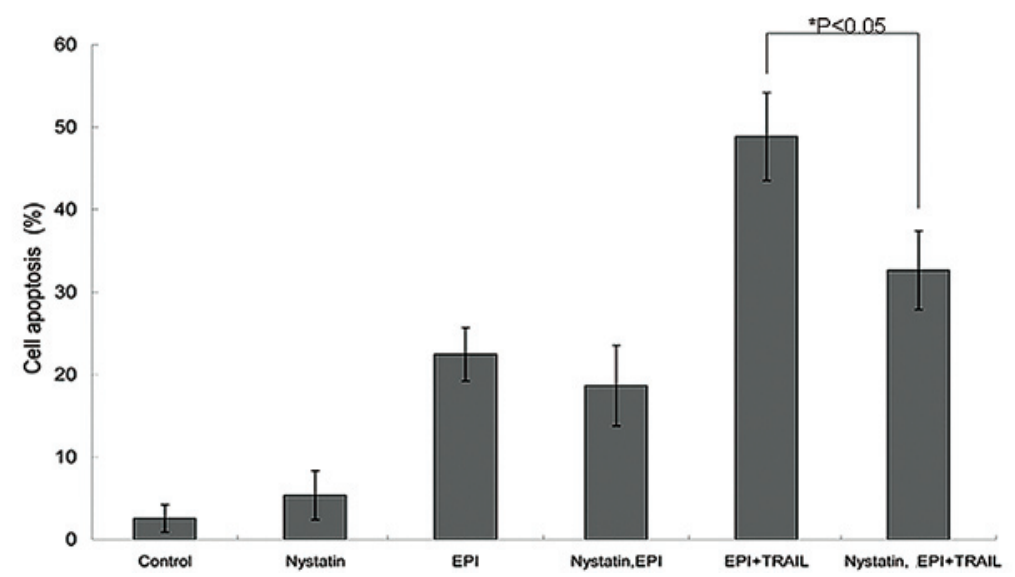

Figure 3. Nystatin partially prevented epirubicin-induced lipid raft aggregation and DR4 and DR5 clustering, and reduced apoptosis in MGC803 cells. (A) Cells were either exposed to $50 \mu \mathrm{g} / \mathrm{ml}$ nystatin for $1 \mathrm{~h}$ or not, then left untreated or treated with $1.18 \mu \mathrm{g} / \mathrm{ml}$ epirubicin, or a combination of $1.18 \mu \mathrm{g} / \mathrm{ml}$ epirubicin and $100 \mathrm{ng} / \mathrm{ml}$ TRAIL, for $16 \mathrm{~h}$. Localization of lipid rafts, DR4 or DR5 was visualized using confocal fluorescence microscopy. Representative images. Original magnification, $\mathrm{x} 40$. (B) Cells were either exposed to $50 \mu \mathrm{g} / \mathrm{ml}$ nystatin for $1 \mathrm{~h}$ or not, then left untreated or treated with $1.18 \mu \mathrm{g} / \mathrm{ml}$ epirubicin, or a combination of $1.18 \mu \mathrm{g} / \mathrm{ml}$ epirubicin and $100 \mathrm{ng} / \mathrm{ml}$ TRAIL, for $24 \mathrm{~h}$. The percentage of apoptotic cells was quantitated by flow cytometry. 
treatment with epirubicin alone (Fig. 1C). These results indicated that epirubicin enhanced TRAIL-induced apoptosis in MGC803 cells through activation of caspases.

Epirubicin promotes DR4 and DR5 clustering into lipid rafts in MGC803 cells. To assess the distribution of death receptors in the cell membranes, confocal fluorescence microscopy was performed using the antibodies against DR4, DR5 and lipid rafts. As shown in Fig. 2, DR4, DR5 and lipid rafts showed a diffuse distribution pattern in the cell membranes of the control cells. The exposure of MGC803 cells to TRAIL for $16 \mathrm{~h}$ induced only light lipid raft aggregation and DR4 and DR5 clustering. However, treatment with epirubicin significantly promoted lipid raft, DR4 and DR5 aggregation, as well as the localization of DR4 and DR5 in the lipid rafts. Combined treatment with epirubicin and TRAIL also induced DR4 and DR5 clustering in aggregated lipid rafts. These results suggest that epirubicin-induced death receptor aggregation in the lipid rafts of the MGC803 cells was the result of the synergetic antitumor mechanism of epirubicin and TRAIL.

Nystatin partially prevents epirubicin-induced lipid raft aggregation and DR4 and DR5 clustering, and decreases apoptosis in MGC803 cells. To investigate the effects of lipid raft aggregation on cell apoptosis, nystatin, a cholesterolsequestering agent that disrupts the lipid rafts, was used. The results showed that treatment with $50 \mu \mathrm{g} / \mathrm{ml}$ nystatin did not influence the distribution of DR4 and DR5 in the lipid rafts of the MGC803 cells. Notably, pretreatment with nystatin partially prevented lipid raft aggregation and DR4 and DR5 clustering induced by epirubicin or epirubicin and TRAIL (Fig. 3A). Pretreatment with nystatin did not markedly inhibit epirubicin-induced apoptosis; however, nystatin partially suppressed epirubicin and TRAIL-induced apoptosis, and the rate of cell apoptosis decreased from $48.86 \pm 5.33 \%$ to $32.65 \pm 4.76 \%(\mathrm{P}<0.05)$ (Fig. 3B). These results indicate that epirubicin-induced death receptors clustering in lipid rafts facilitated TRAIL-induced apoptosis in MGC803 cells.

\section{Discussion}

Recent studies have shown that Jurkat cells are sensitive to TRAIL. When Jurkat cells are incubated with $100 \mathrm{ng} / \mathrm{ml}$ TRAIL for $6 \mathrm{~h}$, the proportion of apoptotic cells is more than $50 \%$ (18). However, most gastric cancer cells are insensitive to TRAIL. Yang et al reported that when SGC7901 cells were exposed to $300 \mathrm{ng} / \mathrm{ml}$ TRAIL for $24 \mathrm{~h}$, the proportion of apoptotic cells was only $11.80 \%$ (19). In the present study, when MGC803 cells were treated with $100 \mathrm{ng} / \mathrm{ml}$ TRAIL for $24 \mathrm{~h}$, the inhibition rate of cell proliferation was only $9.76 \pm 2.39 \%$, and the proportion of apoptotic cells was no more than $6 \%$. These results indicate that MGC803 cells are insensitive to TRAIL. Accordingly, it is necessary to use some agents to sensitize MGC803 cells to TRAIL.

Epirubicin has been shown to achieve satisfactory effects in the treatment of patients with advanced gastric cancer. It has been reported that epirubicin increases the sensitivity of renal cell carcinoma cell lines to TRAIL-induced apoptosis (20). However, whether epirubicin is capable of sensitizing gastric cancer cells to TRAIL has yet to be determined. In the present study, epirubicin significantly enhanced TRAILinduced apoptosis in MGC803 cells. Furthermore, the combination of TRAIL and epirubicin induced even more notable activation of caspase- 3 and -8 . These findings suggest that epirubicin sensitizes MGC803 cells to TRAIL through the activation of caspases. The up-regulation of receptor expression, the increase of DISC-mediated signaling and the alteration of intracellular signal transduction are regarded as the synergetic antitumor mechanisms of chemotherapeutic drugs and TRAIL (21-24). However, these synergistic mechanisms are very complex and not completely understood.

Lipid rafts are cholesterol-enriched microdomains in the cell membrane. It has been reported that the effective aggregation of lipid rafts provides a platform for TRAIL receptor function, and then contributes to TRAIL-induced apoptosis (25). Thus, we may elucidate the function of lipid rafts by investigating the synergistic mechanisms of chemotherapeutic drugs and TRAIL. Certain agents, such as cisplatin, edelfosine and perifosine, may cause receptors to cluster into lipid rafts $(26,27)$. A recent study showed that doxorubicin increases the sensitivity of breast cancer cells to TRAIL by clustering TRAIL receptors into lipid rafts (17). In the present study, epirubicin significantly promoted the clustering of DR4 and DR5 into the lipid rafts in MGC803 cells. The cholesterolsequestering agent nystatin partially prevented lipid raft aggregation and DR4 and DR5 clustering, and reduced the apoptosis induced by TRAIL and epirubicin. These findings indicate that epirubicin-induced DR4 and DR5 redistribution in lipid rafts facilitates TRAIL-induced apoptosis in MGC803 cells.

In conclusion, our results show that epirubicin enhanced TRAIL-induced apoptosis in MGC803 cells. The synergistic mechanism of epirubicin with TRAIL operated partially through death receptor redistribution in the lipid rafts. Lipid rafts probably become vital targets for facilitating TRAILinduced apoptosis in gastric cancer cells.

\section{Acknowledgements}

This study was supported by a grant from the National Natural Science Foundation of China (no. 30770993), the Specialized Research Fund for the Doctoral Program of Higher Education (no. 20102104120008), and a fund for scientific research from The First Hospital of China Medical University (no. fsfh1003). We thank Jian Gao (Experiment Technology Center of China Medical University) for kindly providing technical support.

\section{References}

1 Tsai JY and Safran H: Status of treatment for advanced gastric carcinoma. Curr Oncol Rep 5: 210-218, 2003.

2 Wagner $\mathrm{AD}$, Grothe $\mathrm{W}$, Haerting $\mathrm{J}$, et al: Chemotherapy in advanced gastric cancer: a systematic review and meta-analysis based on aggregate data. J Clin Oncol 24: 2903-2909, 2006.

3 Koornstra JJ, Jalving M, Rijcken FE, et al: Expression of tumour necrosis factor-related apoptosis-inducing ligand death receptors in sporadic and hereditary colorectal tumours: potential targets for apoptosis induction. Eur J Cancer 41: 1195-1202, 2005.

4 Scaffidi C, Fulda S, Srinivasan A, et al: Two CD95 (APO-1/Fas) signaling pathways. EMBO J 17: 1675-1687, 1998.

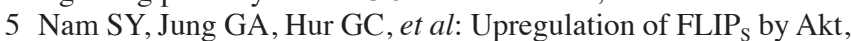
a possible inhibition mechanism of TRAIL-induced apoptosis in human gastric cancers. Cancer Sci 94: 1066-1073, 2003.

6 Sheikh MS, Huang Y, Fernandez-Salas EA, et al: The antiapoptotic decoy receptor TRID/TRAIL-R3 is a p53-regulated DNA damage-inducible gene that is overexpressed in primary tumors of the gastrointestinal tract. Oncogene 18: 4153-4159, 1999. 
$7 \mathrm{Xu} \mathrm{L}, \mathrm{Qu}$ X, Zhang Y, et al: Oxaliplatin enhances TRAIL-induced apoptosis in gastric cancer cells by CBL-regulated death receptor redistribution in lipid rafts. FEBS Lett 583: 943-948, 2009.

8 Scheel-Toellner D, Wang K, Singh R, et al: The death-inducing signaling complex is recruited to lipid rafts in Fas-induced apoptosis. Biochem Biophys Res Commun 297: 876-879, 2002.

9 Muppidi JR, Tschopp J and Siegel RM: Life and death decisions: secondary complexes and lipid rafts in TNF receptor family signal transduction. Immunity 21: 461-465, 2004.

10 Simons K and Vaz WL: Model systems, lipid rafts, and cell membranes. Annu Rev Biophys Biomol Struct 33: 269-295, 2004.

11 Song JH, Tse MC, Bellail A, et al: Lipid rafts and nonrafts mediate tumor necrosis factor related apoptosis-inducing ligand induced apoptotic and nonapoptotic signals in non small cell lung carcinoma cells. Cancer Res 67: 6946-6955, 2007.

12 Asakuma J, Sumitomo M, Asano T, et al: Selective Akt inactivation and tumor necrosis factor-related apoptosis-inducing ligand sensitization of renal cancer cells by low concentrations of paclitaxel. Cancer Res 63: 1365-1370, 2003.

13 Wu XX, Jin XH, Zeng Y, et al: Low concentrations of doxorubicin sensitizes human solid cancer cells to tumor necrosis factor-related apoptosis-inducing ligand (TRAIL)-receptor(R)2mediated apoptosis by inducing TRAIL-R2 expression. Cancer Sci 98: 1969-1976, 2007.

14 Woods DC, Alvarez C and Johnson AL: Cisplatin-mediated sensitivity to TRAIL-induced cell death in human granulosa tumor cells. Gynecol Oncol 108: 632-640, 2008.

15 Sumpter K, Harper-Wynne C, Cunningham D, et al: Report of two protocol planned interim analyses in a randomised multicentre phase III study comparing capecitabine with fluorouracil and epirubicin with cisplatin in patients with advanced oesophagogastric cancer receiving ECF. Br J Cancer 92: 1976-1983, 2005.

16 Cunningham D, Starling N, Rao S, et al: Capecitabine and oxaliplatin for advanced esophagogastric cancer. N Engl J Med 358 36-46, 2008

17 Aroui S, Brahim S, Hamelin J, et al: Conjugation of doxorubicin to cell penetrating peptides sensitizes human breast MDA-MB 231 cancer cells to endogenous TRAIL-induced apoptosis. Apoptosis 14: 1352-1365, 2009.
18 Weng C, Li Y, Xu D, et al: Specific cleavage of Mcl-1 by caspase-3 in tumor necrosis factor-related apoptosis-inducing ligand (TRAIL)-induced apoptosis in Jurkat leukemia T cells. J Biol Chem 280: 10491-10500, 2005.

19 Yang LQ, Fang DC, Wang RQ, et al: Effect of NF-kB, survivin, Bcl-2 and caspase 3 on apoptosis of gastric cancer cells induced by tumor necrosis factor related apoptosis inducing ligand. World J Gastroenterol 10: 22-25, 2004.

$20 \mathrm{Wu}$ XX, Ogawa O and Kakehi Y: Sensitization of human renal cell carcinoma cell lines to TRAIL-induced apoptosis by anthracyclines. Int J Urol 11: 164-170, 2004.

21 Shankar S and Srivastava RK: Enhancement of therapeutic potential of TRAIL by cancer chemotherapy and irradiation: mechanisms and clinical implications. Drug Resist Updat 7: $139-156,2004$

22 LeBlanc H, Lawrence D, Varfolomeev E, et al: Tumor-cell resistance to death receptor-induced apoptosis through mutational inactivation of the proapoptotic Bcl-2 homolog Bax. Nat Med 8: 274-281, 2002

23 Ganten TM, Haas TL, Sykora J, et al: Enhanced caspase-8 recruitment to and activation at the DISC is critical for sensitization of human hepatocellular carcinoma cells to TRAIL-induced apoptosis by chemotherapeutic drugs. Cell Death Differ 11: S86-S96, 2004

24 Muhlethaler-Mottet A, Bourloud KB, Auderset K, et al: Drug-mediated sensitization to TRAIL-induced apoptosis in caspase-8-complemented neuroblastoma cells proceeds via activation of intrinsic and extrinsic pathways and caspase-dependent cleavage of XIAP, Bcl-xL, and RIP. Oncogene 23: 5415-5425, 2004.

25 Psahoulia FH, Drosopoulos KG, Doubravska L, et al: Quercetin enhances TRAIL-mediated apoptosis in colon cancer cells by inducing the accumulation of death receptors in lipid rafts. Mol Cancer Ther 6: 2591-2599, 2007.

26 Gajate C and Mollinedo F: Edelfosine and perifosine induce selective apoptosis in multiple myeloma by recruitment of death receptors and downstream signaling molecules into lipid rafts. Blood 109: 711-719, 2007

27 Lacour S, Hammann A, Grazide S, et al: Cisplatin-induced CD95 redistribution into membrane lipid rafts of HT29 human colon cancer cells. Cancer Res 64: 3593-3598, 2004. 